\title{
A Measure of Adaptation to Problematic Academic and Interpersonal Tasks of Middle School
}

\author{
Maurice J. Elias, Michael Ubriaco, and Ann M. Reese \\ Rutgers University
}

\author{
Michael A. Gara \\ University of Medicine and Dentistry of New Jersey- \\ Community Mental Health Center at Piscataway \\ Peggy A. Rothbaum \\ John F. Kennedy Medical Center, Edison, New Jersey
}

\author{
Martha Haviland \\ University of Michigan
}

\begin{abstract}
This study examined the development and validation of a measure of adaptation to problematic academic and interpersonal tasks that arise during the transition to middle school (Survey of Adaptational Tasks of Middle School-SAT-MS). In terms of Bronfenbrenner's framework of "ecological transitions," a set of psychosocial tasks was reliably identified, and the perceived impact of these tasks was found to be related to self-concept and perceived school environment. Sex differences consistent with differential developmental expectations emerged. The results suggested that for girls, peer relationship tasks were most salient with regard to criterion measures, whereas for boys, peer relationship, conflict with authority, and academic pressure tasks all related to criterion measures. The major findings were replicated for both a predominantly white, suburban sample and a predominantly urban, nonwhite sample. The results are discussed in terms of the needs of children during periods of adaptational challenge.
\end{abstract}

Inquiry into those aspects of the school environment that provide barriers to children's successful academic and interpersonal functioning is clearly increasing. There is a growing realization that numerous "hassles" (i.e., microstressors, or brief, frequently occurring life situations that require immediate adaptation or coping) faced by students during the school day can have a deleterious impact on adjustment (Lazarus \& Folkman, 1984). During transitions from one school to another there is a confluence of factors that heighten the adaptational demands on students: unfamiliar physical environment, largely new set of peers and adults with whom to interact, uncertainty about

Received March 14, 1989; final revision received July 1, 1991.

Address correspondence and reprint requests to Maurice J. Elias, Ph.D., Department of Psychology, Livingston Campus, Rutgers University, New Brunswick, NJ 08903. 
new rules, routines, and performance expectations, and lack of knowledge concerning support resources and how to access them (Felner, Ginter, \& Primavera, 1982). Taken together, thesc demands show that entering a new school meets Bronfenbrenner's (1979) criteria for an ecological transition. That is, entering a new school is a situation in which significant role changes occur and, with these changes, a concomitant likelihood that a previous adaptational balance may be threatened.

Several important studies have empirically demonstrated a link between the normative transition to high school (Felner et al., 1982) and middle or junior high school (Elias, Gara, \& Ubriaco, 1985; Mitman \& Packer, 1982; Simmons, Blythe, Van Cleave, \& Bush, 1979) and an increased incidence of school maladjustment, as well as a negative impact on a significant number of children who had previously been asymptomatic (Toepfer \& Marani, 1980). Thus, there are facets of the receiving environment that are systematically associated with increased dysfunction on the part of many schoolchildren.

It is useful to conceptualize school transitions as embodying a set of psychosocial tasks to which students must adapt (i.e., come to some satisfying and socially acceptable resolution or mastery). These tasks include solving logistical concerns (e.g., learning the new physical layout of the school), developing new relationships with peers, teachers, and adult disciplinary authorities, learning to respond to new interpersonal dilemmas (e.g., pressures to smoke, drink, or take drugs; dating; lockerroom arrangements during gym class), and, of course, finding ways of meeting new and increased academic expectations (Mergendoller, Swarthout, \& Packer, 1982; Pumfrey \& Ward, 1976; Sabo, 1983). During the preadolescent period, adaptation difficulties are exacerbated by biological changes associated with the onset of puberty, cognitive changes associated with an increased capacity for formal operational thinking, and devclopmental changes in relationships with peer and authority figures (Garmezy, 1983; Maccoby, 1983). The confluence of adaptational tasks and biological, cognitive, and developmental changes makes transition to middle school a critical phenomenon in respect to effective prevention, children's mental health programs and policy, and the study of stress and coping in children (Johnson, 1980).

Moos (1984) and Johnson (1986) emphasize that cognitive appraisal of life events and of the adaptational tasks required provides a potent window onto the psychological impact of ecological and developmental transitions. Appraisals incorporate generalized and specific expectancies about an event, its likely outcome, and one's own ability to cope in a positive manner (Lazarus \& Folkman, 1984). Therefore, it is probable that an event appraised as problematic would be associated with a subjective sense of discomfort or distress and or a sense that some special coping efforts may be required. The extent to which such an appraisal translates into clearly observable difficulties in 
adjustment is the outcome of its operation in a set of interactive processes involving available and perceived supports, characteristics of relevant social environments, and personal characteristics (Moos, 1984).

An approach to assessment derived from this perspective would emphasize the concept of adaptational tasks. Such tasks would be developmentally predictable and have a relatively high likelihood of being genuine "stressors." Examples include moving to a larger school, having more homework, having many different teachers, being pressured by peers to smoke, and becoming interested in dating. Such tasks can serve as "items" in an assessment.

Because the occurrence of transition-related tasks across children is relatively uniform, individual differences in appraisal can be meaningfully examined. Although ratings given by children are subjective, all children can be asked to respond from a standardized frame of reference. Work by Johnson (1986) suggests that a framework based on ratings of how often one has to cope with tasks is likely to be less reliable than one based on ratings of how problematic a particular task is for a child. A score that reflects overall severity or impact of perceived problems should have integrity; however, because school ecology is assumed to be multifaceted, a measure should allow children to reflect distinctions in their appraisal of adaptation to different categories of adaptational tasks (Garmezy, 1987; Rutter, 1983).

An assessment tool would have significance for research and practice, particularly in the area of school psychology. It would promote the study of the processes of transition and adaptation related to middle school, and would provide a standard means for identifying the nature and extent of students' adaptational difficulties.

This report presents the development and validation of a measure, based on the aforementioned perspective, of adaptation to problematic academic and interpersonal tasks that arise in middle school.

\section{METHOD}

\section{Overview of Scale Development}

The basic principles for measure development followed a behavioral-analytic and social-learning model, emphasizing behavior-in-situations, rather than respondent traits or attributes, as a unit of analysis (Goldfried \& D'Zurilla, 1969; Rotter, 1954). Therefore, the initial focus was on understanding situations faced by students making transition to middle school. Varied sources were consulted: literature on the characteristics of middle school (e.g., Johnson, 1980), reports of diaries kept during the transition period (Pumfrey \& Ward, 1976), anthropological reports of the school day as seen by middle school youngsters (Sabo, 1983), measures reported in the literature, observa- 
tions of normative developmental phenomena of middle-school-age youngsters (Newman \& Newman, 1984), and literature on risk factors for substance abuse and psychopathology (Botvin, 1983; Bry, 1982; Rutter, 1980).

In addition, informal meetings were held with (a) community mental health center clinicians and private practitioners who treat middle school children, (b) groups of middle school children, and (c) elementary and middle school teachers and administrators. The information obtained was put into statements reflecting the tasks with which students would have to cope upon entering middle school, such as eating in a larger cafeteria, forgetting one's locker combination, being made fun of in the lockerroom, and having harder schoolwork. The statements preserved the children's language wherever possible. In all, 33 statements were used. The criteria for task selection were strong consensus among respondents that (a) a task occurred frequently during the transition, (b) a task occurred to most students, or (c) when a task did occur, it engendered severe coping difficulties.

Piloting of varying formats showed that children seemed to be confused by a multistep procedure that asked for ratings of whether an event occurred, how much distress it led to, and whether it was easy or hard to cope with. It was determined that tasks would be placed in a format in which children would be asked to think about what had occurred over the previous month (with some specific date or event given to mark the time period, e.g., "since you began middle school") and to rate the extent to which a given task was a problem for them. Their choices: no problem, small problem, medium problem, large problem. (The order of problem statements was varied to avoid response sets.) This procedure was chosen to emphasize an assessment of the child's appraisal of the extent to which a task was a source of distress and required ongoing efforts to adapt. As a result of analyses of response frequency and single-item/total-score correlations, 28 tasks were retained on the final version of the measure.

\section{STUDY 1}

\section{Participants and Setting}

A middle school of approximately 550 youngsters (Grades 6-8) was selected for the study. The school was suggested by regional and county educators as "modal": Four elementary schools fed into it. The suburban community of 15,000 was multiethnic (predominantly white, of Italian and Eastern European ancestry; $5 \%$ black and Latino) and predominantly blue-collar, and it was at or above average in the region in terms of rates of separation and divorce, use of mental health facilities, and other concomitants of economic difficulty. Assessments were given to all sixth graders (except 3, who did not have parental permission) -78 boys and 77 girls - just over a month after their entry into the middle school. On average, the children were approximately 1 year above grade level on standard academic indices. 


\section{Measures}

In addition to the assessment of middle school adaptation described earlier, the following measures were used.

Piers-Harris Self-Concept Scale for Children. The Piers-Harris (Piers, 1969) contains 80 true-false items covering areas such as intellectual and school status, positive behavior, popularity, low anxiety, and physical attractiveness. A modified 44-item scale was used in which ambiguous or redundant items were eliminated. The modified scale has an internal consistency of .85 , and a 6 -month test-retest reliability of $r=.73$; it has been validated against peer measures of social competence and children's ability to persist in problem solving in the face of obstacles (Elias, Beier, \& Gara, 1989).

AML. The AML (Cowen \& Associates, 1975) is a rating scale completed by teachers. It covers the domains of acting-out, moodiness, and learning. For the purposes of this study, each child was rated by two teachers (their agreement was $93 \%$ ); one overall behavior rating score was obtained. In previous studies, the AML has shown acceptable reliability and validity (e.g., Janes \& Hesselbrock, 1978).

Achievement. Report card records for the students were obtained for the major academic areas for the first marking period in middle school. A factor analysis revealed that all scores loaded strongly on one factor; therefore, a composite factor score representing achievement was created. In addition, school records concerning absence and tardiness were obtained.

Adjustment to Middle School. The students were asked to respond to the following direct questions: How much do you like middle school $(1=$ very much, $3=i t$ 's ok, $5=$ not at all)? How long has it taken you to get used to middle school $(1=$ a few days, $2=1-2$ weeks, $3=1$ month, $4=$ not used to it $y e t)$ ? How hard has it been to change from elementary to middle school $(1=$ very easy, $3=$ a little easy and a little hard, $5=$ very hard $)$ ? The students were also given 15 bipolar adjectives drawn from descriptive studies about secondary schools and asked to rate each one along a 7-point scale, using "middle school" as the reference point. The adjectives used: good-bad; interesting-boring; comfortable-uncomfortable; unfair-fair; like-hate; sad-happy; nervous-relaxed; friendlyunfriendly; exciting-dull; very confusing-not confusing at all; afraid-unafraid; violentpeaceful; easy-hard; small-big; dangerous-safe. Excellent reliability has been consistently reported for measures of this kind (Wiggins, 1973).

\section{Validation Procedure}

In the initial phase of data analysis, the psychometric structure of the Survey of Adaptational Tasks-Middle School (SAT-MS) was explored through item analysis and factor analysis. The relationship of SAT-MS performance to 
academic ability was also examined. In the second phase, the relationship of indices derived from the SAT-MS to other indices logically expected to relate to $\mathrm{S} \Lambda \mathrm{T}$-MS scores was investigated by means of correlational techniques. These indices included self-concept, perceptions of the middle school environment, and school-related prosocial behavior. It was expected that children who reported lower levels of difficulty on the SAT-MS would be more likely to see the middle school in a positive light, be seen by teachers as welladjusted, and have a positive self-concept.

Analyses were also conducted to look at differential findings for boys and girls. It was expected that the psychometric structure of the SAT-MS would be similar for all children, but that sex differences might emerge in external validity findings. Specifically, it was expected that girls might find adaptational tasks in the area of peer relationships to be most salient, in light of data that indicate that girls' friendship networks are close-knit and intimate and are the focal point for most of their psychosocial concerns in early adolescence (Berndt, 1982; Rutter, 1980). Therefore, a high degree of adaptational difficulty in the peer domain would be most strongly linked to external indices. Because preadolescent boys show equivalent concern about friendships, relationships with adults, and schoolwork, it was hypothesized that in general, predictive relationships of SAT-MS scores to external indices would be higher for boys than for girls and that subareas of adaptational tasks would be associated with external indices at a similar magnitude.

\section{Results (Study 1)}

Psychometric Structure. An intercorrelation matrix of all 28 itcms was computed, as well as a total score, Adaptation Difficulty, derived by adding the scores for each item. The alpha coefficient for the total score was .92. The correlations of each item to the total score with that item removed ranged from .18 to .67 , with 19 items between .48 and .58 . The average interitem correlation was .29. To examine the structure of the SAT-MS, a principal components factor analysis was conducted, with varimax rotation of all factors with an eigenvalue greater than 1.00 . While eight factors were uncovered, accounting for $68 \%$ of the variance, an inspection of the scree plot suggested that the first five factors (which accounted for nearly $60 \%$ of the variance) represented a parsimonious solution. The factor analysis therefore was run again with a five-factor solution. Total scores for each of the five factors were derived by adding the scores of those variables with loadings of at least .33 on a given factor; there were no cross-loading variables. Coefficient alphas were calculated and, on the basis of the alphas and single-item/total-score correlations, four sets of items showed sufficient convergence to be labeled as categories of adaptational tasks: Substance Abuse (alpha $=.93$ ), Peer Relationships (.76), Conflicts With Authorities and Older Students (.85), and Academic Pressures (.61). The remaining items generally related to the logistics of ad- 
justing to a new, larger school. The intercorrelation of the four category scores ranged from .25 to .50 , suggesting that these scores tap related but mostly distinct domains.

Table 1 contains a listing of the tasks, the question number on the SAT-MS form, and the category of task to which each individual item is best related. Table 2 presents descriptive statistics for the total score and the category

Table 1

Tasks on the Survey of Adaptational Tasks of Middle School

$\begin{array}{lll}\text { Task } & \text { Task Name } & \text { Category of tasks } \\ \text { No. } & \text { Tas }\end{array}$

1. Getting lost and not being able to find your way around school

2. Forgetting your locker combination

3. Being treated more like a child

4. Having school farther away from home

5. Having a tough teacher

6. Buying new notebooks

7. Having to do harder school work

8. Eating in a larger cafeteria

9. Having an argument with a teacher

10. Being sent to the vice principal

11. Leaving the wrong books and supplies in your locker and forgetting to bring the right books and supplies to class

12. Getting too much homework

13. Getting into fights

14. Not seeing your friends from elementary school enough

15. Having trouble making new friends

16. Wishing you were in a better reading group

17. Kids trying to talk you into things you don't want to do

18. Getting things stolen from you

19. Being bothered by the older kids

20. Not getting along with all your different teachers

21. Other kids teasing you

22. Not being in the "in" group, like not being able to go around with the group of kids you'd like to hang around with

23. Kids seeing you in the locker room without any of your clothes on and making fun of you

24. Drinking beer, wine or liquor

25. Taking drugs

26. Smoking cigarettes

27. Dating members of the opposite sex

28. Teachers expecting too much of you

Conflicts With Authority, Older Students

Peer Relationships

Conflicts With Authority, Older Students

Academic Pressures

Conflicts With Authority, Older Students

Conflicts With Authority, Older Students

Conflicts With Authority, Older Students

Academic Pressures

Conflicts With Authority, Older Students

Peer Relationships

Peer Relationships

Conflicts With Authority, Older Students

Peer Relationships

Conflicts With Authority, Older

Students

Peer Relationships

Peer Relationships

Substance Abuse

Substance Abuse

Substance Abuse

Peer Relationships 
Table 2

Descriptive Summary of SAT-MS Indices for Full Sample, Boys, Girls

\begin{tabular}{|c|c|c|c|}
\hline Survey indices & $\begin{array}{c}\text { Full } \\
\text { sample }\end{array}$ & Boys & Girls \\
\hline \multicolumn{4}{|c|}{ Adaptation Difficulty } \\
\hline$M$ & 41.05 & 41.50 & 40.58 \\
\hline$S D$ & 12.25 & 12.48 & 12.08 \\
\hline Range & $22-88$ & $22-78$ & $28-88$ \\
\hline \multicolumn{4}{|l|}{ Substance Abuse } \\
\hline$M$ & 3.89 & 3.93 & 3.84 \\
\hline$S D$ & 2.40 & 2.43 & 2.39 \\
\hline Range & $3-12$ & $3-12$ & $3-12$ \\
\hline \multicolumn{4}{|c|}{ Peer Relationships } \\
\hline$M$ & 9.79 & 9.70 & 9.89 \\
\hline$S D$ & 3.73 & 3.65 & 3.84 \\
\hline Range & $7-27$ & $7-23$ & $7-27$ \\
\hline \multicolumn{4}{|c|}{ Conflict With Authority } \\
\hline$M$ & 13.10 & 13.28 & 12.92 \\
\hline$S D$ & 5.23 & 5.20 & 5.28 \\
\hline Range & $8-29$ & $8-29$ & $8-27$ \\
\hline \multicolumn{4}{|c|}{ Academic Pressures } \\
\hline$M$ & 3.46 & 3.76 & 3.17 \\
\hline$S D$ & 1.52 & 1.65 & 1.32 \\
\hline Range & $2-8$ & $2-8$ & $2-7$ \\
\hline
\end{tabular}

scores, for the entire sample and by sex. Note that there are no significant sex differences. Also, the factor analysis structure and pattern of reliability coefficients were equivalent for boys and girls. Finally, the achievement score, derived from report card records of academic ability, was found not to be associated with overall performance on the SAT-MS, $r=.10$ for boys, .14 for girls, NS.

External Validation. Data reduction to obtain criterion variables. External validation involved determining the association of survey indices with variables that represent self-concept, perceptions of middle school, and school-related prosocial behavior. Data reduction was necessary to minimize spurious findings because of overlap among variables and to eliminate multicollinearity. First, a principal components factor analysis was performed on the 15 bipolar adjectives. Three factors accounted for over $90 \%$ of the variance: seeing the middle school as generally (a) good (good, comfortable, interesting, friendly), (b) safe (safe, not violent, fair), and (c) calm (calm, not confusing, easy). Scores derived from each of these factors were computed. Next, a principal components factor analysis was performed on the factor-derived scores, the direct questions about middle school, the teacher ratings of students' behavior, attendance and tardiness records, and the self-concept score. Three factors 
with eigenvalues greater than 1.00 accounted for $56 \%$ of the variance. A varimax rotation was used to aid interpretation: (a) Positive Self-Efficacy (good self-concept; used to middle school; easy to change) $27.5 \%$; (b) Positive Evaluation of Middle School (good, safe, liked very much) $16.5 \%$; and (c) Positive School Behavior (as evidenced by positive teacher ratings and low absence and tardiness records) $12 \%$. These procedures yielded three sets of criterion variables, composed of nine specific indices.

Interrelationship of $S A T-M S$ indices and criterion variables. To evaluate the relationship of the SAT-MS scores to the criterion variables, factor scores for the three sets of variables noted above were regressed onto the total Adaptation Difficulty score (i.e., the total SAT-MS score). The overall relationship was significant, $F(3,121)=13.31, p<.001, r=.49$. Positive Self-Efficacy and Positive Evaluation of Middle School each accounted for a significant, unique portion of variance, $F(1,121)=31.76, p<.001$ and $F(1,121)=7.91$, $p<.006$, respectively. When this analysis was run separately for boys and girls, the findings were similar, with $r=.54$ and $r=.46$, respectively.

Canonical correlation was used to examine the possibility that differential relationships existed between scores for the four categories of adaptation tasks and the three factor scores. The first canonical variate was significant, $F(12$, $297)=4.97, R_{\mathrm{c}}{ }^{2}=.32$, indicating that difficulties with Peer Relationships, Conflicts With Authorities and Older Students, and Academic Pressures were inversely related to Positive Self-Efficacy and Positive Evaluation of Middle School. However, when this analysis was run separately by sex, some important differences emerged. For boys, the canonical $R_{\mathrm{c}}{ }^{2}=.48, F(12,122)=$ $3.28, p<.001$. The results paralleled the findings for the full sample, only much more clearly. For girls, $R_{\mathrm{c}}{ }^{2}=.21, F(12,156)=2.16, p<.02$. For girls, while all four category scores showed a negative association with Positive Self-Efficacy, the link between difficulties in Peer Relationships tasks and low scores on Self-Efficacy was strongest. Thus, girls' adaptational difficulties were less generalized than those of boys, and their peer relationships were most saliently associated with their sense of efficacy.

To further clarify the multivariate analyses performed, Table 3 shows bivariate correlations of the SAT-MS indices and the external validity variables, separately for boys and girls. A modified Bonferroni procedure (Larzelere \& Mulaik, 1977) applied to the correlation matrices suggests that $r=.35$ can be reliably interpreted as significant. The findings support the multivariate analyses, including the sex differences.

\section{STUDY 2}

\section{Background}

Study 2 was conducted to determine whether the factorial structure of the SAT-MS would remain stable with a very different population of middle school students: sixth graders from a predominantly nonwhite, urban, inner 


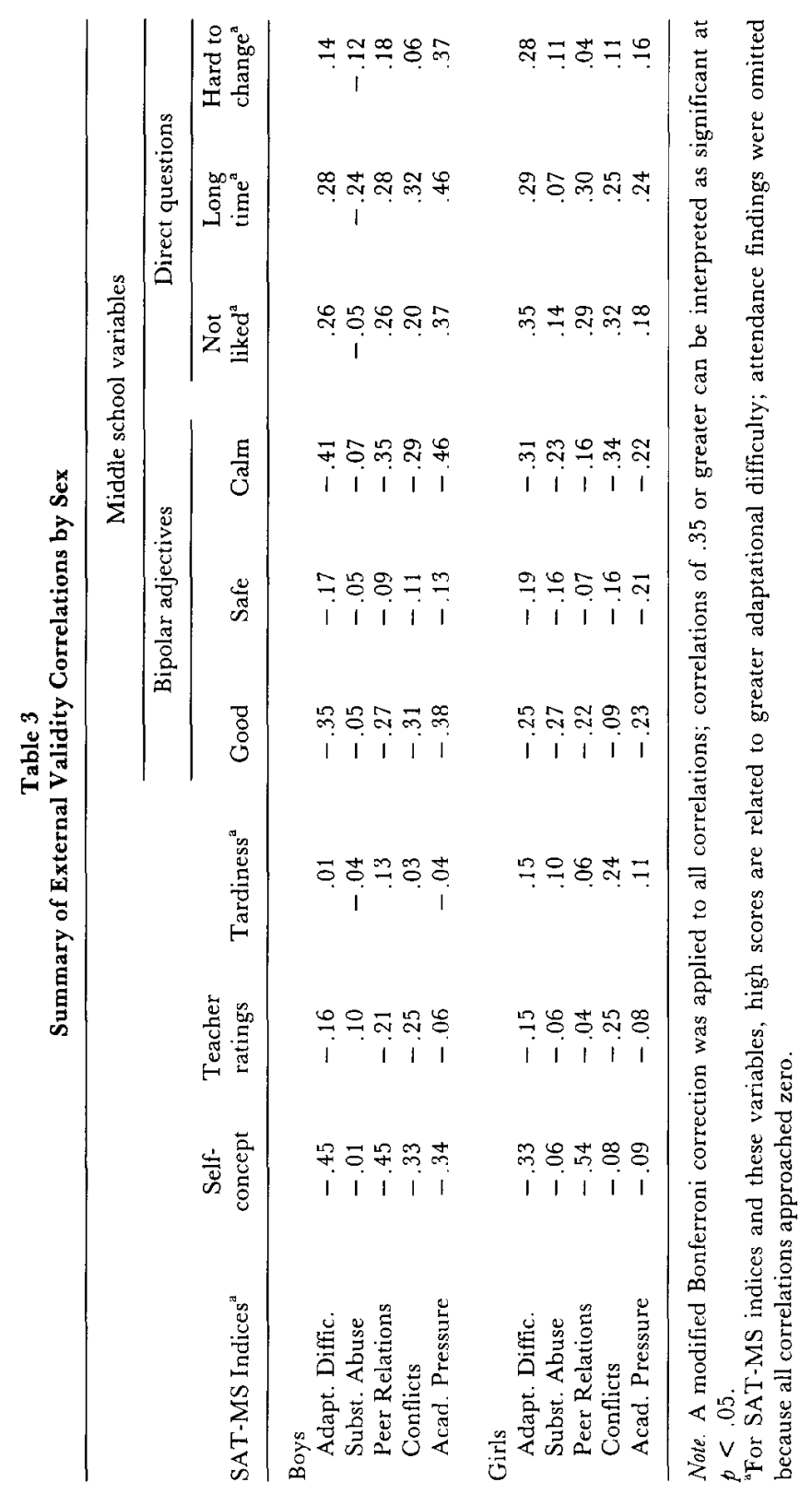


city middle school. Also, there was an interest in further examining the Study 1 findings concerning sex differences in the relationship of the SAT-MS and self-concept. Specifically, work by Garmezy and Masten suggests that when children experience numerous stressors, there is a general tendency to perceive themselves as less competent; this tendency is particularly marked among disadvantaged youngsters (Masten, 1986). Also, developmentally, girls would be expected to be better able than boys to compartmentalize their perceptions, so that their perceived competence would be diminished primarily in areas in which they were experiencing adaptational difficulty (Masten \& Garmezy, 1985).

\section{Participants and Setting}

A middle school of approximately 500 students was selected. It is located in an urban area categorized in the lowest levels of socioeconomic status (SES), with high levels of marital disruption, substance abuse, social mobility, crime, and use of mental health and child welfare services. The children were sixth graders in their first year in the middle school. They were $50 \%$ Latino, $25 \%$ Anglo, 20\% black, and 5\% mixed non-Latino; there were 61 boys and 68 girls. On average, children were at or 1 year below grade level on standard academic indices. Assessment was made 2 months after school began.

\section{Measures}

In addition to the SAT-MS, two subscales of the Perceived Competence Scale for Children (Hartcr, 1982) wcre uscd. Cognitive-academic items addrcss how competent children feel in their school-related work and achievement; socialacceptance items address how competent children believe they are at engaging peers in friendships and groups. Each subscale contains seven items that describe two different groups of children (e.g., kids who are often in groups versus kids who often do things by themselves). A child first decides which type of kids he or she is most like, and then decides whether the description is sort of true or really true for him or her. Items are scored on a 4-point scale, with 1 indicating low perceived competence and 4 indicating high perceived competence. Scores are summed and averaged for each subscale. Satisfactory reliability and validity have been reported consistently (Harter, 1982).

\section{Results (Study 2)}

Analyses of psychometric structure identical to those in Study 1 were conducted with nearly identical results. The principal components factor analysis with varimax rotation again uncovered eight factors accounting for $68 \%$ of the variance. The scree plot again suggested that a 5 -factor solution was most parsimonious, and so the factor analysis was run again, constrained to a 
five-factor solution, as before. The five factors, accounting for $56 \%$ of the variance, contained item loadings that conformed to the factor structure in Study 1. That is, four category scores could be derived as in Study 1, with the exception of two items, one in Peer Relationships (No. 27, Dating Members of the Opposite Sex) and one in Conflict With Authority (No. 2, Forgetting Your Locker Combination). These items had high cross-loadings in this sample. However, coefficient alphas, single-item/total-score correlations, and intercorrelation of the four category scores were nearly the same as in Study 1; the latter, for example, ranged from .17 to .55 .

Table 4 presents descriptive statistics; once again, there were no sex differences. However, the urban sample clearly reported a higher level of problematic adaptational demands. Table 5 presents correlations of the SAT-MS and the Perceived Competence scores. As predicted, girls' scores were highly compartmentalized; adaptation difficulties with peers were associated with lower perceived social competence; difficulties with academics were related to lower perceived cognitive-academic competence. Boys showed more generalized patterns. Lower competence was most consistently linked to peer-related difficulties; however, perceived competence in boys appears to be associated with adaptation difficulty in a wider variety of category areas than is true for girls at this age.

Table 4

Descriptive Summary of SAT-MS Indices for Urban Sample

\begin{tabular}{|c|c|c|c|}
\hline Survey Indices & Full sample & Boys & Girls \\
\hline \multicolumn{4}{|c|}{ Adaptation Difficulty } \\
\hline$M$ & 56.57 & 57.04 & 55.69 \\
\hline$S D$ & 14.43 & 14.23 & 16.16 \\
\hline Range & $29-99$ & $29-92$ & $29-99$ \\
\hline \multicolumn{4}{|l|}{ Substance Abuse } \\
\hline$M$ & 5.99 & 6.41 & 5.64 \\
\hline$S D$ & 3.93 & 4.10 & 3.77 \\
\hline Range & $3-12$ & $3-12$ & $3-12$ \\
\hline \multicolumn{4}{|c|}{ Peer Relationships } \\
\hline$M$ & 13.72 & 13.78 & 13.58 \\
\hline$S D$ & 4.25 & 3.87 & 4.56 \\
\hline Range & $7-23$ & $7-23$ & $7-23$ \\
\hline \multicolumn{4}{|c|}{ Conflict With Authority } \\
\hline$M$ & 17.58 & 18.51 & 16.53 \\
\hline$S D$ & 6.46 & 6.04 & 6.53 \\
\hline Range & $8-32$ & $9-31$ & $8-30$ \\
\hline \multicolumn{4}{|c|}{ Academic Pressures } \\
\hline$M$ & 4.96 & 5.13 & 4.76 \\
\hline$S D$ & 1.84 & 1.85 & 1.80 \\
\hline Range & $2-8$ & $2-8$ & $2-8$ \\
\hline
\end{tabular}


Table 5

Correlation of SAT-MS Indices With Perceived Competence Scale, Urban Sample

\begin{tabular}{llc}
\hline SAT-MS Indices & $\begin{array}{c}\text { Cognitive- } \\
\text { academic }\end{array}$ & $\begin{array}{c}\text { Social } \\
\text { acceptance }\end{array}$ \\
\hline Acceptance & & \\
Boys & $-.26^{*}$ & -.15 \\
$\quad$ Adaptation Difficulty & $-.25^{*}$ & .06 \\
Substance Abuse & $-.33^{* *}$ & $-.43^{* * *}$ \\
Peer Relations & $-.36^{* *}$ & .06 \\
Conflicts & -.21 & $-.33^{* *}$ \\
Academic Pressure & & \\
Girls & -.03 & -.15 \\
Adaptation Difficulty & -.07 & -.05 \\
Substance Abuse & .00 & $-.35^{* *}$ \\
Peer Relations & .06 & .04 \\
Conflicts & $-.33^{* *}$ & -.22 \\
Academic Pressure & & \\
\hline
\end{tabular}

${ }^{2}$ For SAT-MS indices high scores are related to greater adaptational difficulty.

${ }^{* * *} p<.001 . * * 001<p<.01 . \quad * 01<p<.05$.

\section{DISCUSSION}

The Survey of Adaptational Tasks of Middle School appears to provide psychometrically adequate information concerning overall adaptation difficulty and subareas of particular adaptation challenge across at least two distinctive middle school populations. In Study 1 difficulty with tasks related to the transition to middlc school was most closely rclatcd to indicators of students' concerns about the middle school environment and to students' sense of selfefficacy. As predicted, the relationship of SAT-MS indices to external criteria was stronger in boys than in girls, a finding also observed by Compas, Slavin, Wagner, and Vannatta (1986) in a study of the relationship of negative life events to psychiatric symptomatology in adolescents. For girls, peer-related stressors seemed most salient, in accordance with prior hypotheses and developmental expectations.

These relationships generally were confirmed in Study 2. Boys reporting low perceived competence in academic and social domains also reported adaptation difficulties in a variety of areas. Girls' associations seemed more differentiated. Peer-related stressors shared variance with perceived social competence; perceived academic competence was linked with academic task pressures.

Somewhat unexpected was the lack of relationship of SAT-MS indices to adjustment, as represented by teachers' ratings. It is possible that 1 month following the transition may be too soon for teachers to have established a clear sense of most children's behavioral adjustment. At the beginning of the school year, the range of adjustment scores is also attenuated. At later points 
in the school year, one is more likely to tap stable views of both adaptation difficulties and adjustment, and thereby obtain a more valid indication of the relationship between these constructs.

It is also worth noting that students who keep up with their academic work, keep their peer and substance abuse problems out of the classroom, and keep their relationships with their teachers cordial are likely to be viewed as adequately adjusted. This is consistent with Lazarus and Folkman's (1984) position that it is visible coping that is most accessible to objective measurement: Children's appraisal of adaptational difficulties is "phenomenological" (p. 53) and will not necessarily be perceived strongly or accurately by persons in the children's environment. Ultimately, "adjustment" is linked to contextual factors in any measurement setting, as well as to attributes of the children under study. Therefore, sources of information about children's behavior and functioning outside of the classroom should be obtained in future studies.

\section{Implications for Research and Practice}

A survey of adaptational tasks provides an indicator of potential intervention points at both the individual and school levels. There is compelling evidence that even students who leave elementary school with satisfactory levels of social and academic skills may encounter difficulties with the transition to middle school. These difficulties can be profitably understood as tasks that, to be mastered successfully, generally require coordinated and sequenced integration of various skills. Future research no doubt will extend and refine the four adaptation subareas currently identified by the SAT-MS. Nevertheless, combined with additional relevant information, students' SAT-MS responses can assist in focusing individual or group interventions. It can be of particular value that interventions can be made in areas that students themselves identify as problematic; whatever skills-building approaches one might wish to undertake therefore could be initiated around circumstances concerning which students would be relatively highly motivated.

At the building level, patterns of difficulties can be monitored to suggest areas in which organization practices and policies of the school might be modified to allow students to adapt to tasks more successfully. Felner and Adan (1988) modified the organization of secondary schools to create less flux in student groupings and increase contact with a core set of teachers during the first years in the school. These changes were responses to anecdotal reports of difficulties with academic pressures and conflicts with authorities and older students. While not causative per se, patterns of difficulties in adaptation tasks also might suggest preventive interventions. In a pilot school for the development of the SAT-MS, data concerning the tasks associated with logistical difficulties, academic pressures, and conflict with authorities were used by school and community psychologists and educators to plan a self-organiza- 
tional/study skills course for all students entering middle school and to develop and refine existing programs in the elementary schools designed to promote children's interpersonal problem-solving and social decision-making skills, particularly upon entry into middle school (Elias \& Tobias, 1990).

In light of the findings from the initial study and these considerations, future research should have several foci. First, a broader array of indices of school adjustment should be used, to allow an increased range of variability and a multimethod/multisource assessment of that construct. Second, the relationship of adaptation difficulty to another variable closely linked with adaptational challenges, namely social support, should be explored. Particularly among early adolescents, the support of a best friend is likely to foster coping with interpersonal and academic difficulties (Thoits, 1986). Support variables are potential buffers of the impact of adaptational difficulty on adjustment, as well as potential sources of influence on the developmental progress of coping with problematic tasks of middle school (Heller, Swindle, \& Dusenbury, 1986).

Future work also should involve collecting a broader base of normative data on the SAT-MS. This would include a differential examination of the link of SAT-MS scores with grades, standardized achievement tests, and indices of academic aptitude or intelligence. These and related research questions can be enriched by administering the SAT-MS at different lengths of time after transition to middle school and also by looking at results as a function of different types of sending and receiving environments.

In summary, at this point, the Survey of Adaptational Tasks of Middle School is most appropriately used as a way of understanding the areas of middle school life to which children believe they are having difficulty adapting. The data show that these difficulties are consistently linked with the children's perceptions about the middle school, the process of getting used to the school, and children's self-concept and perceived competence. In settings in which the salience and awareness of children's emotional well-being is very high, there is likely to be a generally stronger relationship of SAT-MS indices with overall indices of school adjustment. Differentiating such contextual possibilities from measurement error constitutes an area in which much vigilance and further work are required.

\section{ACKNOWLEDGMENTS}

This research was supported in part by grants to the first author from the William T. Grant Foundation, the Schumann Fund for New Jersey, and the National Institute of Mental Health. The authors wish to thank Dana DeMaso, Abner Garcia, the educators and children of our participating schools, a very talented Improving Social Awareness-Social Problem Solving actionresearch team, and the diligent secretaries at Tillett Hall. 


\section{REFERENCES}

Berndt, T. J. (1982). The features and effects of friendship in early adolescence. Child Development, 53, 1447-1460.

Botvin, G. J. (1983). Prevention of adolescent substance abuse through the development of personal and social competence. In T. J. Glynn, C. G. Leukefeld, \& J. P. Ludford (Eds.), Preventing adolescent drug abuse: Intervention strategies (pp. 115-140). Rockville, MD: NIDA, Office of Science.

Bronfenbrenner, U. (1979). Contexts of child rearing: Problems and prospects. American Psychologist, 34, 844-850.

Bry, B. (1982). Reducing the incidence of adolescent problems through preventive intervention: One- and five-year follow-up. American Joumal of Community Psychology, $10,265-276$.

Compas, B. E., Slavin, L., Wagner B., \& Vannatta, K. (1986). Relationship of life events and social support with psychological dysfunction among adolescents. Journal of Youth and Adolescence, 15, 205-221.

Cowen, E., Trost, M., Izzo, L., Lorion, R., Dorr, D., \& Isaacson, R. (1975). New ways in school mental health: Early detection and prevention of school maladaptation. New York: Human Sciences Press.

Elias, M. J., Beier, J., \& Gara, M. (1989). Children's response to interpersonal obstacles as a predictor of social competence. Journal of Youth and Adolescence, 18, 451-465.

Elias, M. J., Gara, M., \& Ubriaco, M. (1985). Sources of stress and coping in children's transition to middle school: An empirical analysis. Joumal of Clinical Child Psychology, 14, 112-118.

Elias, M. J., \& Tobias, S. (1990). Problem solving/decision making for social and academic success: A school-based approach. Washington, DG: National Education Association.

Felner, R., \& Adan, A. (1988). The School Transitional Environment Project: An ecological intervention and evaluation. In R. Price, E. Cowen, R. Lorion, \& J. Ramos-McKay (Eds.), 14 ounces of prevention: $A$ casebook for practitioners (pp. 111122). Washington, DC: American Psychological Association.

Felner, R., Ginter, M., \& Primavera, J. (1982). Primary prevention during school transitions: Social support and environmental structure. American Joumal of Community Psychology, 10, 277-290.

Garmezy, N. (1983). Stressors of childhood. In N. Garmezy \& M. Rutter (Eds.), Stress, coping, and development in children (pp. 43-84). New York: McGraw-Hill.

Garmezy, N. (1987). Stress, competence, and development: Continuities in the study of schizophrenic adults, children vulnerable to psychopathology, and the search for stress-resistant children. American Joumal of Orthopsychiatry, 57, 159-174.

Goldfried, M., \& D'Zurilla, T. (1969). A behavioral-analytic model for assessing competence. In C. Spielberger (Ed.), Current topics in clinical and community psychology (Vol. 1, pp. 151-196). New York: Academic Press.

Harter, S. (1982). The Perceived Competence Scale for Children. Child Development, $53,87-97$.

Heller, K., Swindle, R., \& Dusenbury, L. (1986). Component support processes: Comments and integration. Journal of Consulting and Clinical Psychology, 54, 466-470.

Janes, C. L., \& Hesselbrock, V. (1978). Problem children's adult adjustment predicted from teachers' ratings. American Journal of Orthopsychiatry, 48, 300-309.

Johnson, J. H. (1986). Life events as stressors in childhood and adolescence. Beverly Hills, CA: Sage.

Johnson, M. (Ed.) (1980). Toward adolescence: The middle school years. Seventy-ninth yearbook of the National Society for the Study of Education (pp. 7-31). Chicago: University of Chicago Press. 
Larzelere, R., \& Mulaik, S. (1977). Single sample test for many correlations. Psychological Bulletin, 84, 557-569.

Lazarus, R., \& Folkman, S. (1984). Stress, appraisal, and coping. New York: Springer.

Maccoby, E. (1983). Social-emotional development and response to stressors. In N. Garmezy \& M. Rutter (Eds.), Stress, coping, and development in children (pp. 217234). New York: McGraw-Hill.

Masten, A. (1986, August). Patterns of adaptation to stress in middle childhood. Presentation at the annual meeting of the American Psychological Association, Washington, DC.

Masten, A., \& Garmezy, N. (1985). Risk, vulnerability, and protective factors in developmental psychopathology. In B. Lasky \& A. Kazdin (Eds.), Advances in clinical psychology (Vol. 8, pp. 1-52). New York: Plenum.

Mergendoller, J. R., Swarthout, D., \& Packer, M. (1982). Lipsticks and backpacks: Life as a seventh-grader. Journal of Early Adolescence, 2, 389-414.

Mitman, A., \& Packer, M. (1982). Concerns of seventh-graders about their transition to junior high school. Journal of Early Adolescence, 2, 319-338.

Moos, R. H. (1984). Context and coping: Toward a unifying conceptual framework. American Journal of Community Psychology, 12, 5-36.

Newman, B., \& Newman, P. (1984). Development through life: A psychosocial approach (3rd ed.). Homewood, IL: Dorsey.

Picrs, E. (1969). Manual for the Piers-Harris Self-Concept Scale for Children. Nashville, TN: Counselor Recording and Tests.

Pumfrey, P., \& Ward, J. (1976). Adjustment from primary to secondary school. Educational Research, 19, 25-34.

Rotter, J. B. (1954). Social learning and clinical psychology. Englewood Cliffs, NJ: Prentice-Hall.

Rutter, M. (1980). Changing youth in a changing society: Patterns of adolescent development and disorder. Cambridge, MA: Harvard University Press.

Rutter, M. (1983). Stress, coping, and development: Some issues and some questions. In N. Garmezy \& M. Rutter (Eds.), Stress, coping and development in children (pp. 142). New York: McGraw-Hill.

Sabo, L. (1983). Child-based observation in a middle school: Data from an observational study using the approaches of Sarason, Lauffer, Goffman, $\mathscr{E}^{2}$ Moos. New Brunswick, NJ: Rutgers University Social Problem Solving Project.

Simmons, R. G., Blythe, D., Van Cleave, E., \& Bush, D. (1979). Entry into early adolescence: Impact of school structure, puberty, and early dating on self-esteem. American Sociological Review, 44, 948-967.

Thoits, P. A. (1986). Social support as coping assistance. Joumal of Consulting and Clinical Psychology, 54, 416-423.

Toepfer, C., \& Marani, J. (1980). School based research. In M. Johnson (Ed.), Toward adolescence: The middle school years. Seventy-ninth yearbook of the National Society for the Study of Education (pp. 269-281). Chicago: University of Chicago Press.

Wiggins, J. S. (1973). Personality and prediction. Reading, MA: Addison-Wesley. 